Jpn. J. Oral. Biol., $28:$ 120-123, 1986.

\title{
Microanatomical study on the parotid duct of Macaca irus
}

\author{
Yasunori Takeda, Akira Fujimura* and Yohichiro Nozaka* \\ Department of Oral Pathology and *Oral Anatomy I, School of Dentistry, \\ Iwate Medical University, Uchimaru 19-1, Morioka 020, Japan
}

[Accepted for publication: December 4, 1985]

Key words : Parotid duct/Macaca irus/microanatomy

Many studies have been made so far on physiological and morphological (histological, histochemical and ultrastructural) observations of the human and animal salivary glands in health and diseases. However, none of them have made reference to the function and microscopic structure of the main excretory duct of major salivary glands.

We previously reported microanatomical findings of the main excretory ducts of the human parotid gland (called Stensen's or Stenon's duct) taken from postmortem subjects ${ }^{1}$. The present paper reports the results of microanatomical examination of the parotid duct taken from Macaca irus.

\section{Materials and Methods}

The parotid ducts were taken from a healthy Macaca irus (male; body weight, $12 \mathrm{~kg}$ ). After sacrifice by intravascular perfusion using a physiological saline solution and $10 \%$ neutral-buffered formalin under general anesthesia, both the right and left sides of parotid ducts were dissected carefully, and they were cut between the anterior border of the parotid gland and the masseteric anterior portion. These resected parotid ducts were preserved in $10 \%$ neutral-buffered formalin, and embedded in paraffin in a routine manner. Thin sections were stained with hematoxylin and eosin, orcein and Azan-Mallory staining methods, and prepared for light microscopic observation to investigate the following factors: 1) mucosa, 2) duct lumen, 3) muscular layer, 4) outer connective tissue layer, and 5) vessels and nerves.

\section{Result}

The parotid duct of Macaca irus possessed three histological coats: mucosa, muscular layer and outer connective tissue layer (adventitia) (Fig. 1).

\section{1) Mucosa}

The mucosa of the parotid duct was composed of a thin mucous epithelial layer (two to three epithelial cell layers in thickness), a basement membrane, and a thin subepitelial connective tissue layer (Fig. 2-4). The luminal surface was smooth and no papillary projections were found in any region. These epithelial cells of the innermost layer consisted of two types of epithelial cells (Fig. 2). One was of columnar cells with numerous cilia and a large oval nucleus which was usually located in the central portion of the cytoplasm.

The other was of goblet cells containing a large amount of mucous substance in its cytoplasm, and their nuclei were compressed into the basal area. Transitional cells between the former epithelial cells and the latter ones were also observed.

In part, evidence of extensive proceeding of mucous secretion was found (Fig. 3), and a large amount of mucous substance filled the duct lumen in such regions. The basal cell layer consisted of cuboidal cells with large nucleus, and the basal surface was smooth without rete peg formation. There were no metaplastic changes of the epithelial cells such as squamous or transitional epithelial cells. The basement membrane was thin, but observed distinctively.

The subepithelial thin connective tissue layer contained abundant elastic fibers and a small amount of dense collagenous fibers. The elastic fibers were in close vicinity to the epithelial layer, and were situated around 


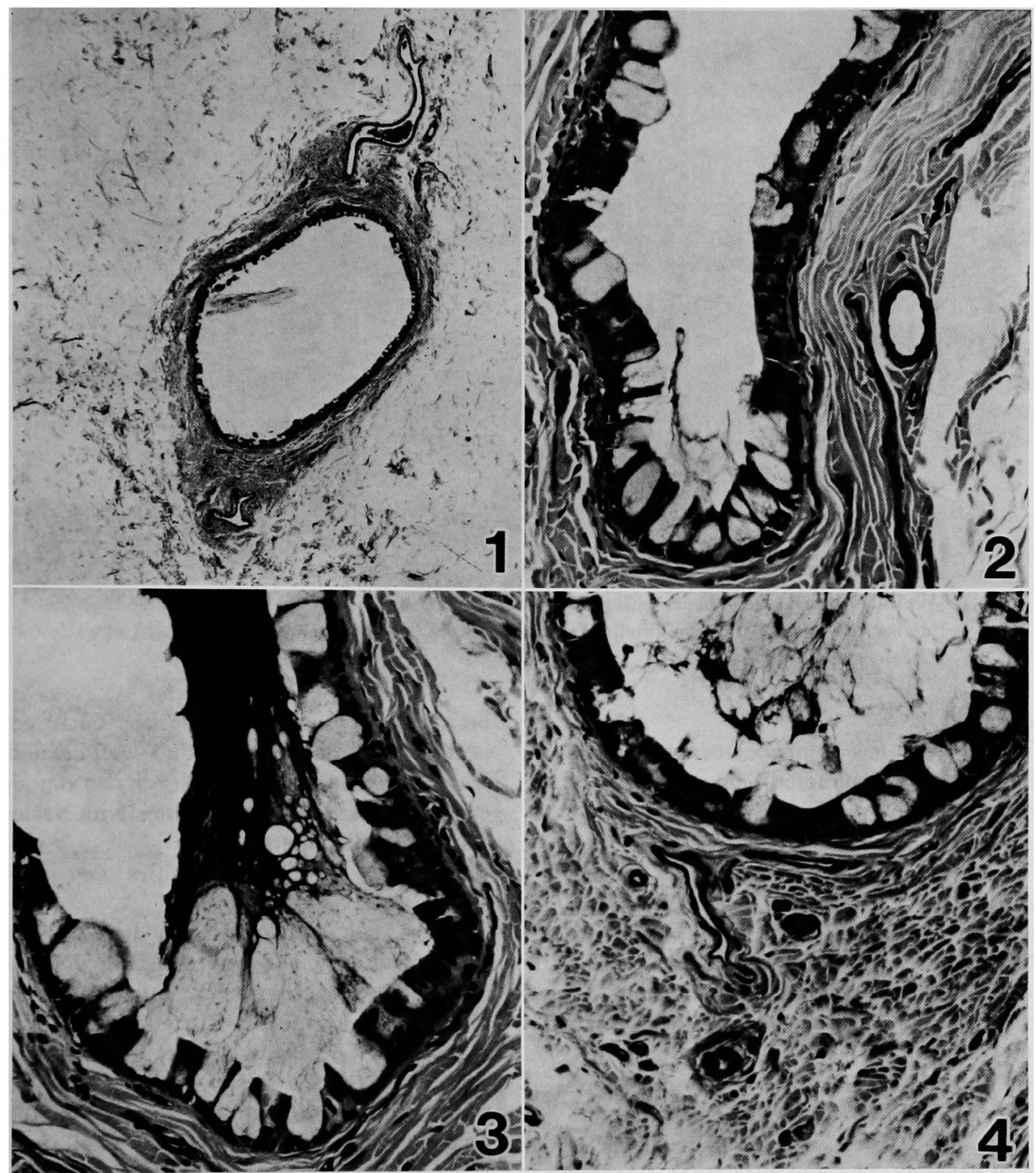

Fig. 1 Whole view of cross section of the parotid duct of Macaca irus showing three histological coats : mucosa, muscular layer and outer connective tissue layer. H.E. stain.

Fig. 2 Mucous epithelium of the parotid duct consisting of innermost cells (columnar cells and goblet cells) and cubical basal cells. No lymphoid cell infiltration in the subepithelial connective tissue layer and in the muscular layer. H.E. stain.

Fig. 3 Extensive production of mucous secretion by goblet cells. H.E. stain.

Fig. 4 Cross section of the parotid duct showing longitudinal orientation of the smooth muscle fibers in the muscular layer. Small vessels and nerve fibers are noted in the muscular layer. H.E. stain, 


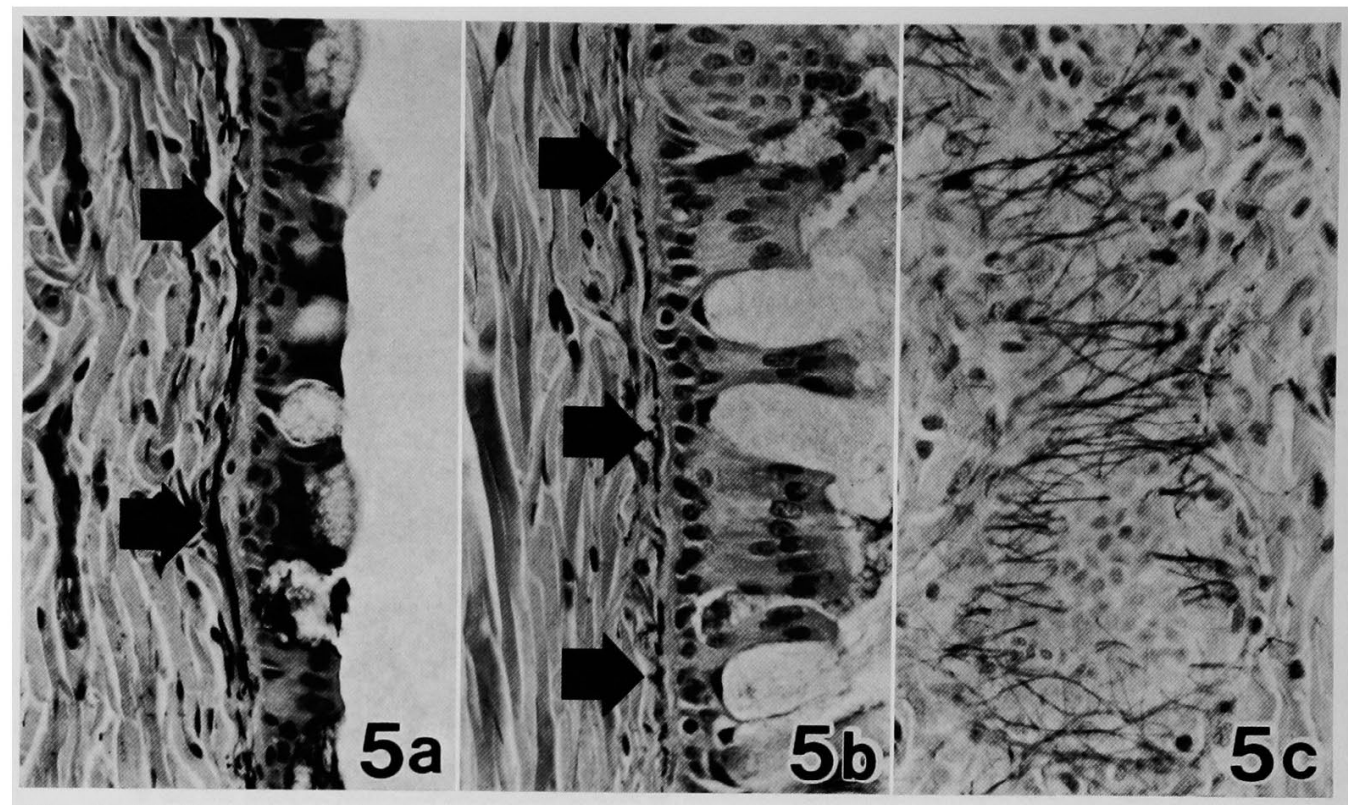

Fig. 5 Well-developed elastic fibers with a circular arrangement, in close vicinity to the epithelium. (a) is cross section (b) is longitudinal section, and (c) is longitudinal section cut tangentically. Orcein stain.

the duct (Fig. 5).

There were few lymphocytes and plasma cells in the subepithelial connective tissue layer.

2) Duct lumen

The duct lumen was round to oval in outline, and contained various amounts of salivary condensates, but there were no inflammatory cells, exudates, necrotic cell debris, crystalloids or bacterial aggregates. The luminal surface was smooth, and no papillary projections were formed.

3) Muscular layer

The border between the subepithelial connective tissue layer and the muscular layer was ill-defined. The muscular layer consisted of smooth muscle fibers running in a longitudinal direction (Fig. 1-4). The muscle fibers appeared in relatively small bundles. Oblique muscle fibers admixed with longitudinal ones were noted frequently, but circular muscle fibers were not found in any region.

4) Outer connective tissue layer (adventitia)

The outer connective tissue layer was of various thicknesses and consisted of lipofibrous connective tissue (Fig. 1). The border between the muscular layer and outer connective tissue layer was rather well-defined. The outer connective tissue layer also contained blood vessels and lymphatics with various degrees in diameters.

5) Blood vessels, lymphatics and nerve fibers

Veins and lymphatics run parallel with the parotid duct, and were noted in the outer connective tissue layer, muscular layer and subepithelial connective tissue layer (Fig. 1, $2,4)$. In the muscular layer and the outer connective tissue layer these veins and lym. phatics were dilated to varying degrees. Small veins and arteries and small nerve fibers were recognized in the muscular layer and in subepithelial connective tissue layer, but nerve terminal fibers could not be demonstrated in the present examination.

\section{Discussion}

Although there have been many reports of the morphology of the main excretory ducts of the human and animal major salivary glands studied by macroscopical anatomy, casting by the use of synthetic resin, and sialography ${ }^{2,3)}$, none have made references to the 
histology and physiology of the parotid duct and the other main excretory ducts of the major salivary glands. We made a histological study of the human parotid duct previ. ously $^{11}$, and reported that the human parotid duct possessed three histological coats, i.e., mucosa, muscular layer and outer connective tissue layer, and such histological structure resembled the excretory passage of the ureter. In the present study, histoarchitecture of the parotid duct of Macaca irus was basically similar to that of human parotid duct. But there are a few histological differences between the parotid duct of the human and Macaca irus, i.e., 1) vascular system in outer connective tissue layer was well-developed in human, 2) numerous goblet cells which appeared not to be correlated with chronic inflammation were observed in the innermost epithelial layer of Macaca irus.

In conclusion, the results of the previous and the present studies suggest that the main excretory duct of major salivary glands contribute to control of salivary secretion, since their histoarchitecture is basically similar to that of other ducts or canals which have peristaltic activities.

\section{Acknowledgement}

This study was supported in part by Grant-in-Aid for Developmental Scientific Research (60570854) from the Education Ministry, Japan.

\section{References}

1) Takeda, Y., Fujimura, A., Nozaka, Y.: Microanatomical study of the human parotid duct. Jpn. J. Oral Biol. 26 : 1350-1352, 1984.

2) Kamjio, Y.: Atlas of Oral Anatomy No. 5 (in Japanese), 2 nd ed., pp. 1501-1512, Anatom Co., Tokyo, 1971.

3) Odajima, G.: Morphological studies on the parotid (Stensen's) duct of the Japanese (in Japanese). Jpn. J. Oral Biol. $14: 465-481$, 1972. 